\title{
Cooperativismo autogestionario de hábitat y asociativismo vecinal. El caso del Programa de Autogestión de la Vivienda de la Ciudad de Buenos Aires (Argentina)
}

\author{
Self-managed cooperativism of habitat and neighborhood \\ associations. The case of the Housing Self-Management Program of \\ the City of Buenos Aires (Argentina)
}

\section{María Cecilia Zapata ${ }^{1}$}

Fecha de recepción: 07-02-2021 - Fecha de aceptación: 20-04-2021

Hábitat y Sociedad (ISSN 2173-125X), n. ${ }^{\circ}$ 14, noviembre de 2021, pp. 139-158.

http://dx.doi.org/10.12795/HabitatySociedad.2020.i13.08

\section{Summary}

Since the 2000s, the City of Buenos Aires (Argentina) has implemented the Housing Self-Management Program (PAV), which promotes self-managed habitat production through the granting of collective loans to grassroots social organizations. The existing housing cooperative bank allows us to reflect on the self-managed forms used by the organizations and their impact on the neighborhood relationships built in the stage of living in the dwellings. From the deployment of a qualitative methodology, various primary sources of information produced in different research stages were recovered and analyzed from an approach that seeks to contribute to the current debates of the self-managed production of popular habitat. Among the results obtained, it was possible to verify that the forms assumed by the self-management process in the housing production stage have impacts on the base conditions for the construction of neighborhood associations typical of living.

\section{Key words}

Habitat; Production and Social Management of Habitat; Citizen Participation; Neighborhood Relations; Cooperativism; Self-management

\section{Resumen}

Desde los años 2000 en Ciudad de Buenos Aires (Argentina) se ejecuta el Programa de Autogestión de la Vivienda (PAV), el cual promueve la producción autogestionaria de hábitat mediante el otorgamiento de créditos colectivos a organizaciones sociales de base. El banco de cooperativa de viviendas ya existente permite reflexionar sobre las formas autogestoras esgrimidas por las organizaciones y su impacto en las relaciones vecinales construidas en la etapa del habitar de las viviendas. A partir del despliegue de una metodología cualitativa se recuperaron diversas fuentes primarias de información producidas en distintas etapas investigativas y fueron analizadas desde un enfoque que procura aportar a los debates actuales de la producción autogestionaria del hábitat popular. Entre los resultados que se obtienen se pudo verificar que las formas que asume el proceso autogestionario en la etapa de producción de las viviendas tienen impactos en las condiciones de base para la construcción de asociativismo vecinales propios del habitar.

\section{Pallabras clave}

Hábitat; Producción y Gestión Social del Hábitat; Participación Ciudadana; Relación Vecinal; Cooperativismo; Autogestión

1 Socióloga. Dra. en Ciencias Sociales. Investigadora adjunta del CONICET con sede en el Instituto de Investigaciones Gino Germani, Universidad de Buenos Aires / Docente, GAU-DDPT, Universidad Nacional de Lanús. E-mail: ceciliazapata@gmail.com. ORCID: https://orcid.org/0000-0003-0580-693. 


\section{Introducción ${ }^{2}$}

El Programa de Autogestión de la Vivienda (PAV) promovido por la Ley 341/00 en la Ciudad de Buenos Aires (Argentina) fue impulsado por el Instituto de la Vivienda de la Ciudad (IVC) desde el año 2000 hasta la actualidad. Tiene por objetivo otorgar créditos colectivos a organizaciones sociales de base (cooperativas, mutuales $u$ organizaciones sin fines de lucro) a tasas de interés de entre el $0 \%$ y el $4 \%$ - subsidiadas-y plazos de devolución de hasta 30 años. El destino del crédito es el de adquisición de suelo, ejecución de obra de vivienda nueva o reciclaje y contratación de un equipo técnico interdisciplinario (ETI) (Zapata, 2017). Lo virtuoso de esta política de hábitat es que las decisiones propias del proceso productivo de las viviendas quedan en manos de los productores/destinatarios colectivamente organizados, rasgo característico de la autogestión.

Hasta la actualidad, tal como puede observarse en la Figura 1, avanzaron con proyectos de obras unas 110 organizaciones sociales (de una demanda de 516 organizaciones inscriptas en el programa). La ejecución de esta política orientada a la autogestión de hábitat no ha hizo priorizada mediante la asignación de recursos por las diversas gestiones de gobierno frente a la producción tradicional "llave en mano" (Zapata, 2017). ${ }^{3}$ Sin embargo, la presión y resistencia establecida por las organizaciones de base permitió avanzar con un conjunto de proyectos que hoy se constituyen en un banco de experiencias autogestionaria en la CABA y disputan el modelo tradicional de obra pública del Estado. A partir de un seguimiento propio de los indicadores del programa e información ya sistematizada (Pedro, Campari, Di Virgilio, Rodríguez y Zapata, 2020), unas 40 cooperativas lograron adquirir terreno, construir y 1261 familias ya habitan sus viviendas cooperativas en la centralidad de la ciudad. Unas 26 organizaciones tienen sus viviendas cooperativas en distintas instancias de obra, y otras 45 ya cuentan con terreno y la mayoría de ellas ya están en condiciones de iniciar sus obras. (Figura 1)

Esta producción dio cuenta de la capacidad autoproductora de hábitat con la que cuentan los sectores populares, la cual se materializó en complejos habitacionales localizados en plena centralidad urbana y con acceso a las oportunidades asociadas a esta condición (vale aclarar que la ubicación de las cooperativas partió de la decisión de los propios cooperativistas que organizaron cuadrillas de búsqueda de terrenos vacantes en aquellas zonas de interés por sus integrantes). La mayoría de estos complejos tuvieron un promedio de 20 viviendas, pero existen cooperativas tanto de 8 - Coop. Sembrar Conciencia- como de 326 viviendas - Coop. EMETELE del Movimiento Territorial de Liberación (MTL) - , con un promedio de $71 \mathrm{~m}^{2}$ de superficie (muy superior a los estándares establecidos para la vivienda social estatal -51 $\left.\mathrm{m}^{2}-\right)$ y espacios colectivos. Se distinguen del resto de las viviendas sociales por sus calidades y diseños constructivos, los bajos costos de producción (un $40 \%$ menos que la vivienda social al mismo tiempo producida mediante "llave en mano" por el estado local (Zapata, 2017)) y por la diversidad de esquemas productivos que habilitó. Hubo cooperativas que decidieron impulsar sus procesos productivos mediante la contratación de cooperativas de trabajo, otras que avanzaron con ejecución de obra mediante contrataciones directas de los diversos rubros u oficios, e incluso algunos grupos decidieron firmar contratos con pequeñas empresas constructoras o empresas familiares o generar su propia cooperativa de trabajo. La mayoría de las cooperativas incorporaron en

Hábitat en áreas metropolitanas del Norte y el Sur Global: políticas, instituciones y movilización social” Ref.: (PID2019 105205RB-100), financiado por el

Ministerio de Ciencia, Innovación y Universidades (España).

3 Para profundizar en el peso relativo de esta política con relación al resto de las políticas habitacionales ejecutadas a escala local, se puede ver el capítulo 4 y 5 de Zapata (2017). 


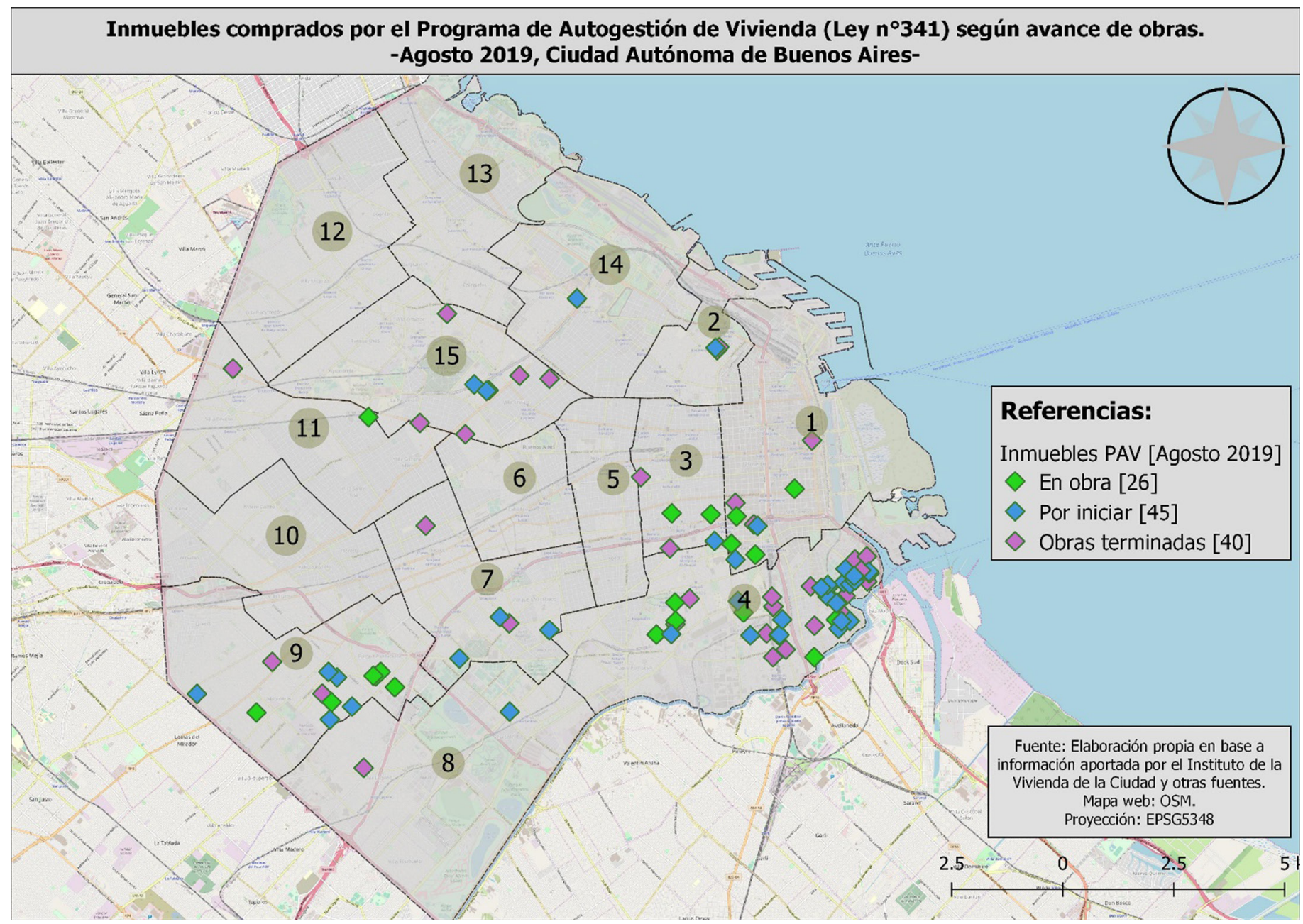

los planes de obra actividades de ayuda mutua o jornadas solidarias y, además, aportaron fondos propios complementarios a los del PAV para sostener etapas de desfinanciamiento y mejorar terminaciones.

La flexibilidad que mostró el programa en los modos de producción de los proyectos constructivos encuentra una estrecha relación con las instancias de participación social que habilitó la autogestión. Cada cooperativa decidió las características que asumirían las obras de sus viviendas, consolidando una arquitectura autogestionaria orientada a definir formas de habitar centradas en la vida cotidiana de las/os habitantes y su participación. Por lo que las formas en las que se desarrolló la autogestión del hábitat y las formas de participación social habilitadas en los procesos de diseño y de obra tuvieron impactos en el habitar de las viviendas y —de interés para este artículo— en las capacidades de consolidar asociativismos vecinales positivos para lo que posteriormente es el cuidado y mantenimiento de los conjuntos. Los procesos de construcción de obra se dieron a la par de un proceso de construcción social del colectivo que una vez finalizada la etapa de obra convivirá en los complejos construidos. Esa trayectoria previa de participación, en donde las tomas de decisión nutren prácticas de apropiación, tiene impactos en las formas que posteriormente asume la organización para el cuidado y mantenimiento de los complejos y para la consolidación de procesos de apropiación de lo construido colectivamente.

Con este marco, este artículo tiene por objetivo analizar los escenarios de participación social experimentados por distintas experiencias autogestionarias del Programa de Autogestión de la Vivienda ejecutado desde el 2000 en la Ciudad de Buenos Aires (Argentina), en relación
Figura 1: Mapa de las operatorias ejecutadas en el marco del PAV. Agosto 2019, Ciudad Autónoma de Buenos Aires (Argentina) Fuente: Elaboración propia en base a datos aportados por el IVC. 
con las características que asume el asociativismo vecinal durante el habitar de las viviendas sociales construidas. La hipótesis que se sostiene es el que en aquellas cooperativas en las que se lograron desplegar reales procesos de participación social en sus procesos productivos de vivienda, la construcción de relaciones vecinales propias del habitar se vio facilitada por aquella trayectoria, tanto en la consolidación de las prácticas cotidianas de cuidado de sus edificios como en la resolución de conflictos hacia el interior de sus complejos como hacia el afuera, redundando esto en procesos positivos de apropiación de lo construido.

Para ello se utilizó a una metodología cualitativa de abordaje, en la que se recurrió a una recuperación de distintas fuentes de información producidas en diversos trabajos de campos propios (entre 2010-2015 y 2017-2019) y que el objetivo de este artículo permite revisitarlos desde un nuevo corpus de abordaje. Por un lado, se recuperaron, como fuentes primarias, los trabajos de campos realizados en el marco de mis tesis de maestría (Zapata, 2012) y doctorado (Zapata, 2017) (15 entrevistas en profundidad a destinatarios del PAV con viviendas cooperativas finalizadas, relevamientos fotográficos de obras y notas de campo de entrevistas y recorridas observacionales), y la aplicación de una encuesta a 120 cooperativistas del PAV, ejecutada entre enero y abril de $2018,{ }^{4}$ a integrantes de 9 cooperativas que concentran unas 600 familias (prácticamente el $60 \%$ del total de familias habitantes de complejos habitacionales construidos mediante de la Ley 341 de ese momento). El procesamiento de estas fuentes de información se realizó de manera triangulada, en parte con una estrategia artesanal (a partir de la confección de matrices de análisis) y en parte mediante las facilidades que ofrece el programa Atlas Ti. Valles (1999) decía que en la investigación cualitativa los procedimientos y técnicas de análisis están lejos de poder ser estandarizados; por lo que la técnica de análisis también fue de tipo artesanal. Recurrimos a un análisis temático a partir de la identificación de dimensiones de análisis que respondieran al objetivo propuesto para este artículo y a una estrategia de categorización de los datos obtenidos (Sautú, 1999) que resultaron ordenadores del análisis.

A los fines de organizar este artículo, primeramente, se realizará un recorrido teórico-conceptual por algunos conceptos claves que permitirán introducirnos en debates actuales sobre la autogestión, la participación social y el asociativismo vecinal. Luego se recuperará el trabajo de campo realizado en un grupo de cooperativas seleccionadas (los 45 proyectos que cuentan con obras finalizadas) para analizar la relación objeto de análisis de este artículo. Primero se analizan las formas organizativas desplegadas por las cooperativas para diseñar y ejecutar sus obras y las instancias de participación social construidas para ello, y luego la repercusión de esto en las formas de asociativismo vecinal construido por las cooperativas para el cuidado y mantenimiento de sus complejos y en relación con su integración barrial. Por último, se intentarán algunas reflexiones finales del trabajo realizado, orientadas a aportar evidencia concreta a los debates actuales de la producción autogestionaria de hábitat.

4 La encuesta se desarrolló como producto del Proyecto "Alternative models of housing development programs in Buenos Aires, Argentina", ejecutado por la Universidad Johns Hopkins (dirigido por Valeria Procupez y María Carla Rodríguez) con el Área de Estudios Urbanos del IIGG y Asociación Civil MOI.

\section{Abordajes teóricos de partida}

La expresión urbana del modo de producción capitalista, multiplicación de escenarios de segregación y exclusión, expansión de las periferias y pobreza intersticial en las centralidades urbanas, sentaron 
las bases para el surgimiento de procesos de resistencias en numerosas ciudades, adoptando diversas modalidades y formatos (Newman y Wyly, 2006; Delgadillo Polanco, 2009; Casgrain y Janoschka, 2013; De la Garza, 2014; Rodríguez y Di Virgilio, 2016), entre las que emergió la producción autogestionaria de hábitat (Ortiz Flores, 2002; Rodríguez, 2009). Incluso, la autogestión impulsada en interacción con el Estado también formó parte de algunas experiencias de gobiernos populares en América Latina. La Ley Nacional de Vivienda de 1968 del Uruguay, impulsada por la FUCVAM (Federación Uruguaya de Cooperativas de Vivienda por Ayuda Mutua), asignó un cauce institucional a la producción habitacional autogestionaria en ese país, pero también se constituyó en una de las intervenciones en hábitat de mayor envergadura y continuidad a escala continental. Otras experiencias como las esgrimidas en Brasil o Venezuela también nutren el campo de la autogestión en relación con el ámbito estatal, como alternativa válida de producción de hábitat.

Específicamente en nuestro país (y al igual que en gran parte de América Latina), la política de vivienda estatal priorizó históricamente una modalidad de producción centralizada en el Estado nacional, mediante el modelo productivo "llave en mano". Esta metodología remite a la construcción directa por parte del Estado de viviendas nuevas, en las que intervienen — vía licitación-empresas privadas (nacionales e internacionales o mixtas de distinto tamaño) en la etapa constructiva y técnicos estatales en la etapa de diseño de lo producido. Sin consultas inter-actorales (con destinatarios, por ejemplo) se priorizan tipologías de grandes conjuntos habitacionales en barrios autosuficientes, en localizaciones periféricas, en suelo fiscal o privados adquiridos para proyectos, con deficiente accesibilidad e infraestructura urbana y social. Los destinatarios surgen de una población dispersa, en déficit habitacional, anotada en un listado confeccionado para tal fin por el organismo de vivienda correspondiente y las viviendas son entregadas una vez finalizado el proceso productivo. Las primeras intervenciones habitacionales bajo esta modalidad de producción hay que rastrearlas en la Argentina hacia la época del peronismo de los años cuarenta (Rodulfo, 2003; Fernández Wagner, 2009). A lo largo del tiempo se fueron ensayando distintas tipologías de conjuntos habitacionales que fueron sobre la práctica buscando maximizar la acumulación de capital para los mercados productores, pero a la vez, por sus resultados urbanos, habitacionales y materiales negativos, fueron buscando mejorar las pautas de integración para sus destinatarios (no siempre con éxito). La ausencia de una mirada integral del destinatario final de las viviendas y de sus necesidades, generó una mercancía desvalorizada (por sobre un bien de uso) y condujo a la desatención respecto de dos elementos básicos: la tipología de las viviendas construidas (que por lo general tendió a la homogeneización) y la localización de la población en el territorio (que por lo general tendió a procesos de relocalización). Esto trajo por resultado: situaciones de hacinamiento, alteraciones de lo construido para adaptar las viviendas a las reales necesidades familiares, y procesos de estigmatización, segregación y exclusión social, y creación de fronteras simbólicas entre vecinos de un mismo barrio (Dunowicz y Boselli, 2018). A esto hay que adicionarle que la falta de regularización dominial de las viviendas — una falencia estructural de la estatidad localtuvo por consecuencia tardías y conflictivas organizaciones consorciales (Gentilini et al., 2004) que repercutieron en un abandono edilicio de los complejos por falta de mantenimiento, en la desapropiación de 
las viviendas, los complejos y de los barrios de inserción y relaciones vecinales también conflictivas en cuanto a la gestión de las diferencias. Entonces, la desatención del aspecto social de la política "llave en mano" precarizó las condiciones de reproducción de vida de las familias destinatarias.

Ahora bien, las políticas habitacionales que impulsan la autogestión, constituyen un campo de disputa simbólico y material en el marco de las políticas históricamente ejecutadas en el país. La reestructuración neoliberal del Estado de los años setenta (con su retirada) impactó en términos habitacionales en la apertura de resquicios para el surgimiento de políticas orientadas a la producción autogestionaria de vivienda mediante cooperativas. Esta disputa expresa las contradicciones propias del modelo de producción, en dos de sus facetas: la subordinación del trabajo al capital y la tensión del hábitat como bien de uso o como mercancía. La producción autogestionaria (Ortiz Flores, 2002; Rodríguez et al., 2007), como práctica productora de vivienda estatal, supone una inversión paulatina del Estado ${ }^{5}$ a partir de la transferencia de recursos a organizaciones sociales que autoproducen sus vivienda. Esta práctica productiva se encuentra bajo la promoción y el control directo de las organizaciones sociales que, sin fines de lucro, participan de todas las etapas de la producción de la vivienda; esto es el diseño, la construcción y el habitar. Para ello recurren a estrategias de capacitación, manejo de información, participación en las decisiones y socialización de responsabilidades (Pelli, 1997; Rodríguez et al., 2007; Barreto, 2008), a partir de una priorización del valor de uso de la vivienda, desde una visión integral del hábitat. Como cualquier modelo de producción de vivienda estatal, la producción autogestionaria tiene consecuencias en término políticos (en términos de disputa de las dinámicas institucionales tradicionales), económicos (a partir de la estructuración de nuevos sub-mercados), sociales (a partir de los roles concretos que les toca asumir a los destinatarios a lo largo del proceso y la tipología de usuarios que se configuran) y territoriales (vinculados a las características del hábitat que se produce, la localización y los servicios socio-urbanos que se ofrecen) (Rodríguez et al., 2007). Por lo que esta tipología de política de hábitat se desarrolla en escenarios de disputa en diversos planos y con impactos también variados.

En este sentido, en términos sociales, la producción autogestionaria de vivienda estatal habilita ciertas instancias de participación social en la etapa de obra de las viviendas que tiene impactos profundos en lo materialmente producido (Zapata, 2017); pero también, veremos en este artículo, en las modalidades de sociabilización vecinal para el mantenimiento del habitar y las apropiaciones que se generan de lo producido. Pero es importante señalar que no toda participación impacta de la misma manera. Las diversas modalidades o formatos que adoptó la política habitacional —incluso la autogestionaria- no siempre implicaron nuevas pautas de relacionamiento entre el Estado y la sociedad, donde la participación social se tradujo en habilitante de cambios profundos en la estructura socio-urbana de la ciudad o en la escala del desarrollo de la vida cotidiana de los destinatarios de lo producido. Hilvanar fino en las distintas modalidades de participación social que habilitó la autogestión permite verificar una gradiente con diferencial expresión en el habitar y su organización vecinal.

En este sentido, De la Mora $(1992,2002)$ define a la participación

5 Esto implica a su vez una transformación de la propia institucionalidad estatal (Rodríguez et al., 2007). social como una instancia a través de la cual las personas identifican problemáticas, formulan y negocian alternativas de resolución, par- 
tiendo de la base de que cada alternativa de solución puede responder a los intereses de una gran diversidad de actores sociales. Existe una gran variedad de modalidades de participación en una política social, y su abordaje teórico también proviene de diferentes perspectivas. A pesar de tratarse de instancias de participación que se gestan en el marco de procesos de autogestión, Rofman (2007) advierte que estas modalidades pueden devenir de perspectivas liberales que ponderan la participación de actores no gubernamentales en la gestión a partir del aporte que realizan en términos de eficiencia y transparencia, hasta discursos transformadores - propios de la perspectiva autogestionaria-, que instrumenta mediante estas instancias la posibilidad de toma real de decisiones desde abajo y la reinterpreta como una instancia de ejercicio pleno de ciudadanía. Por lo que los resultados de la participación pueden ser diversos, ya que, si bien pueden dar lugar a experiencias de efectivo empoderamiento social y ampliación de los mecanismos democráticos, también pueden devenir en espacios en los que la participación es reducida a formas tuteladas y controladas de involucramiento, que redundan en un aumento de la legitimidad de la dominación política por sobre un aumento de los procesos de democratización social. Pelli (2007) llama la atención sobre esta cuestión de la "falsa participación" de los destinatarios en las políticas de hábitat, pues técnicos-profesionales intervinientes en los ETI que acompañan procesos de autogestión (empoderados de un saber técnico, profesional y en una posición de mayor poder en la estructura social) actúan convencidos de hacerlo bajo marcos participativos porque existen instancias de opinión de los destinatarios de las viviendas o espacios para la "aprobación" de lo que los técnicos y/o profesionales pensaron por ellos. Pero dichas experiencias participativas (y efectivamente así presentadas) distan de ser un proceso de real participación, ya que la par-

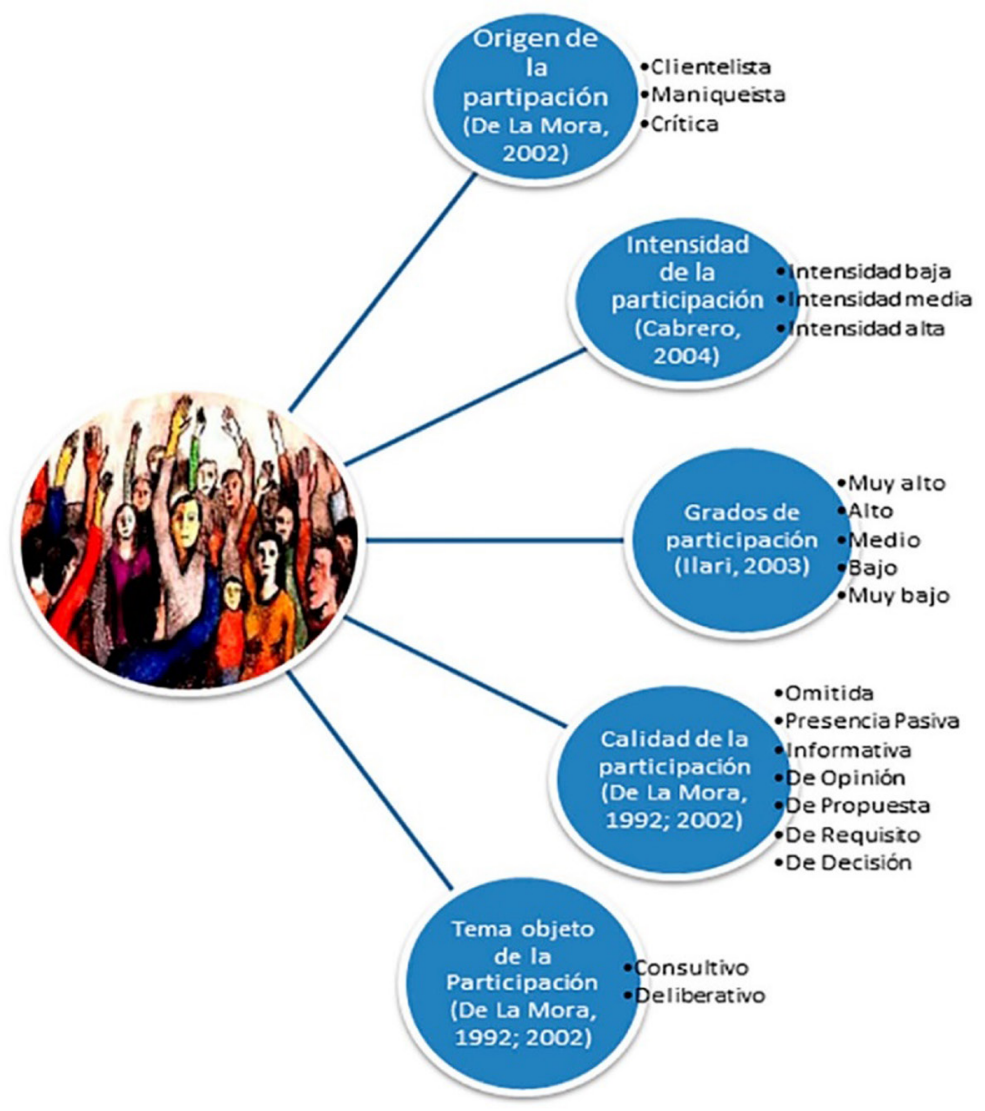

Figura 2: Síntesis de categorías de análisis de participación social. Fuente: elaboración propia en base a De la Mora 1 1992, 2002), llari (2003) y Cabrero (2004). 
ticipación social implica un genuino proceso de toma de decisión por parte de los destinatarios de la política, desde una escala de valores propia (con asesoramiento de un profesional-técnico) y la cual redunda en un proceso de empoderamiento de las subjetividades participantes (Zapata, 2017). Por lo que la posibilidad de la redistribución de las tomas de decisiones es lo que habilita la práctica de genuinos procesos de autogestión del hábitat.

Existen un conjunto de autores especialistas en la temática participación en políticas públicas que ofrecen criterios para analizar y clasificar las experiencias participación y poder así echar luz sobre esta cuestión (Figura 2).

Por lo tanto, el modo de ejecución de la política habitacional autogestionaria, y el tipo de participación que involucró en su proceso productivo, tiene impactos en términos de las posibilidades de apropiación, modos de habitar y usos cotidianos que los destinatarios de las viviendas construidas hacen de ellas. Lefebvre (2003) plantea que el espacio es producido socialmente y que existe un dialéctico condicionamiento entre el espacio urbano y las relaciones sociales que en él de despliegan, ya que las características del espacio condicionan las relaciones sociales, pero a su vez, el espacio urbano es producto de estas. Por lo que Espagnol y Echevarría (2010) agregan que la forma en la que las distintas tipologías de hábitat condicionan los modos de relación, también inciden en las formas de organización social, es decir que existe una mutua vinculación entre el hábitat (espacialidad) y la forma de organización de la vida cotidiana. Estos supuestos nos invita a hipotetizar que el modo en el que se desarrolló el proceso autogestionario de producción de vivienda impacta en el habitar de las familias y en sus formas de organización para la convivencia cotidiana, la sociabilidad vecinal. ${ }^{6}$

\section{Diseños y producción de vivienda en el PAV: un análisis de la participación social.}

El Programa de Autogestión de la Vivienda cuenta con una fuerte impronta participativa por haber sido gestado por procesos de "participación deliberativa" (De la Mora, 1992) de organizaciones sociales relacionadas al hábitat en la Legislatura de la Ciudad. Este antecedente presionó hacia una ejecución del programa mediante formas de producción alternativas de viviendas a las históricamente ejecutadas por la estatidad. El control del proceso productivo estuvo a cargo de organizaciones sociales (principalmente cooperativas) a través de distintos formatos de participación social ejecutados para la gestión de los proyectos constructivos, haciendo uso efectivo de los recursos asignados por el Estado local. Es decir, las organizaciones sociales de base, en el marco del programa, asumieron un rol protagónico de todo el proceso de gestión y producción de las viviendas estatales, con distintos grados de intensidad (Cabrero, 2004) según cada cooperativa.

A los fines analíticos de este artículo, identificamos dos instancias

6 Entendemos por "sociabilidad vecinal" al conjunto de relaciones que entablan personas ajenas al grupo doméstico a partir de la proximidad espacial (Grafmeyer, 1998). Por lo que el estudio de este tipo de relaciones nos introduce en la trama del «estar juntos», en la convivencia y en la gestión de las alteridades propias de la etapa que denominamos "habitar". del proceso de producción de las viviendas autogestionarias que tienen efectos en la etapa del habitar y en las condiciones para el asociativismo vecinal: 1) una de ellas es la etapa de diseño de las viviendas, y la otra, 2) la de producción/construcción propiamente dicha de los complejos de vivienda cooperativos.

Con relación a la primera de estas etapas, el diseño de las viviendas, a partir de las experiencias cooperativas analizadas, se verificó que no 
existe una relación directa entre procesos autogestionario e instancias reales de participación social de los destinatarios de las viviendas en su diseño y concepción. Al contrario de lo que se suponía, que esto sucediera dependió, por un lado, de las características específicas de cada cooperativa (algunas asumieron características más horizontales y otras más verticales); por otro, del modo en que cada una de ellas decidió llevar adelante el proceso autogestionario de obra (algunas ejecutaron sus obras "llave en mano" con pequeñas empresas constructoras y otras - en las antípodas- decidieron conformar su propia cooperativa constructiva); y por último, del modo de trabajo y de ejercicio profesional del/a arquitecto/a (o de él/ella en el marco del ETI), pues estas experiencias se convirtieron en una usina de comprobación del rol fundamental que desempeñan la/os profesionales en la instancia de diseño de viviendas estatales.

En relación a este último aspecto, dentro de las experiencias autogestionadas analizadas se detectaron dos cooperativas constructiva y estéticamente casi similares, verificándose una "participación omitida" (De la Mora, 1992) por parte de sus destinatarios en el diseño de las viviendas. Al consultar en las entrevistas sobre las características que asumió la etapa de diseño de las viviendas, se detectó que ambas cooperativas compartían profesionales del ETI y fundamentalmente, arquitecto. $\mathrm{Al}$ indagar en las modalidades de trabajo se detectó que los espacios de participación generados para el diseño de sus casas, en ambas cooperativas, se limitaron a encuentros informativos sobre las características que tomaría el proyecto constructivo, en donde no se habilitaron instancias para la introducción de modificaciones estructurales al pro-
Figura 3: Cooperativa 18 de junio y Cooperativa Luz y Progreso. Fuente: Tomas propias junto a Kaya Lazarini, 2013.
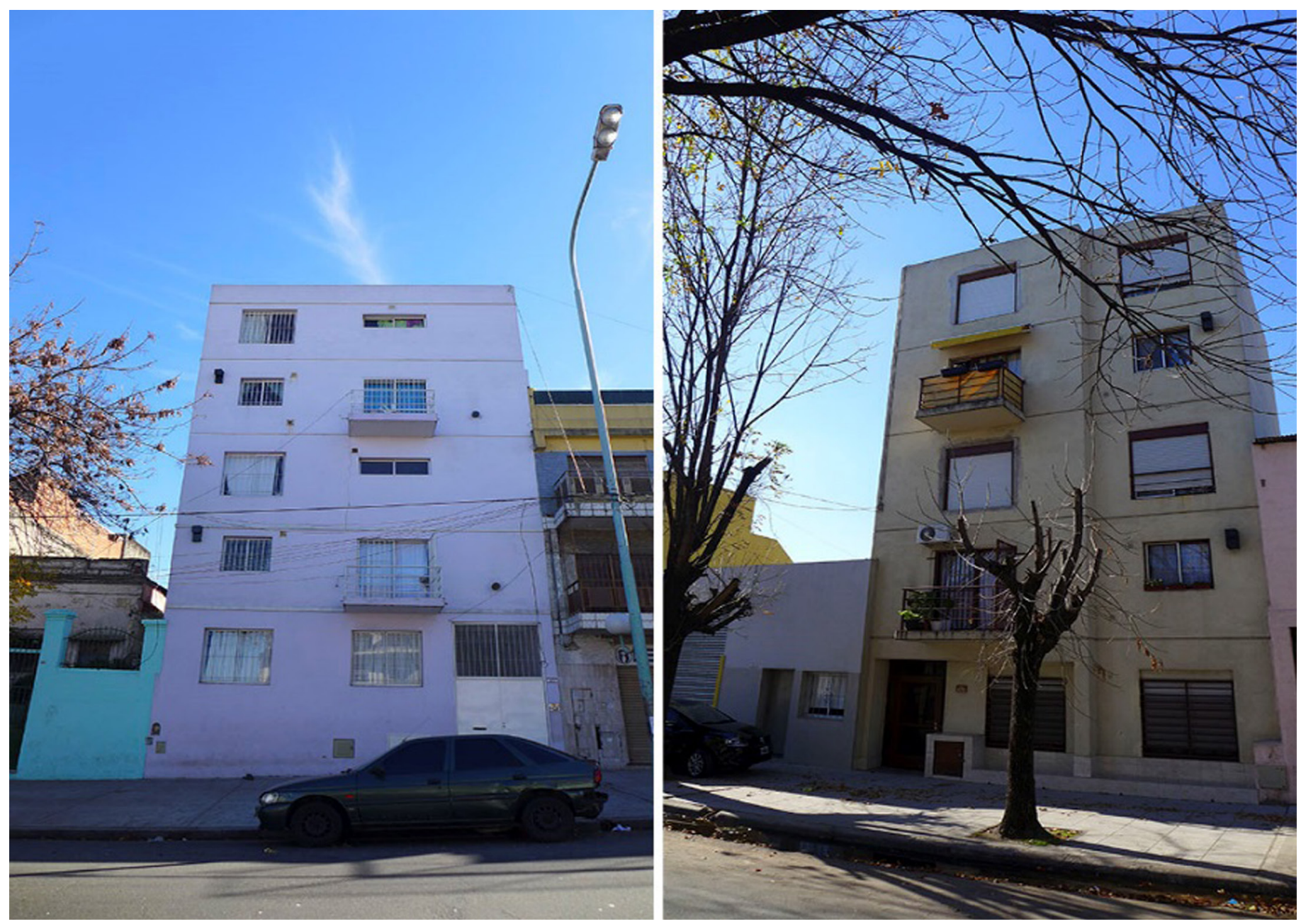
yecto presentado por el arquitecto que se adapten mejor a los gustos y necesidades de las familias destinatarias (solo se habilitaron modificaciones de terminaciones de obras). La imposibilidad de introducción de cambios al proyecto original se justificó mediante un supuesto técnico de poca disponibilidad de espacio y/o reducido presupuesto para realizar modificaciones sustantivas - desde un rol de dominación guiada por una lógica de un saber específico- Tal como puede verse en la Figura 3 a continuación, los proyectos constructivos son prácticamente iguales, donde se ve un proceso de homogeneización del perfil del destinatario y omisión de la participación de los mismos por parte del profesional del ETI. Operó tal una dinámica de proyecto "llave en mano" propio de las políticas tradicionales de hábitat, inhabilitando reales procesos de participación social y tomas de decisiones por parte de la/os cooperativistas.

Más allá de estos casos de omisión participativa, se verificó que gran parte de las cooperativas del PAV contaron con instancias de participación en el diseño de sus viviendas en un formato "consultivo", a partir de espacios que movilizaron desde "prácticas de opinión" hasta "prácticas de decisión" (De la Mora, 1992; 2002), reconociendo intensidades (Cabrero, 2004), grados (Ilari, 2003) y calidades participativas (De la Mora, 1992, 2002) muy variadas. En la mayoría de las experiencias, el diseño de las viviendas surgió de los propios arquitectos de los ETIs que definieron - a priori y de manera autónoma- las características del proyecto en base al censo de familias de las cooperativas (previamente construido por el área social de los ETIs). Con posterioridad, estos diseños preliminares, fueron puestos a consideración por la/os cooperativas para obtener sus opiniones e impresiones y definir así el proyecto definitivo de sus viviendas y complejos habitacionales. Es decir, en la mayoría de los casos, la consulta a la/os cooperativistas sobre el diseño de sus viviendas se dio sobre la base del trabajo previo de los arquitectos. En estas instancias participativas, algunas cooperativas lograron plantear cambios sustantivos a los proyectos originales, e incluso se solicitaron adecuaciones a sus gustos y necesidades; y otras, a pesar de tener esas instancias para realizar modificaciones, no las utilizaron (denotando claramente el poder simbólico con que cuentan los profesionales en estas instancias de participación).

Fue significativo para este análisis verificar cierta falta de capacitación por parte de los profesionales en la captación —vía instancias de participación- de las preferencias y gustos de los moradores de las viviendas como puntos de partida para el ejercicio de su profesión ${ }^{7}$ sin una sensación de deslegitimación de su rol profesional. La formación y capacitación de los profesionales surgió en el análisis como una variable de éxito fundamental de los procesos de autogestión del hábitat. Tal como argumenta Pelli (2007), los profesionales de la arquitectura deben capacitarse en el ejercicio de una arquitectura cooperativa, colectiva o autogestionaria, en la que mediante la utilización de instrumentos y herramientas participativas puedan captar los criterios, preferencias y gustos del hábitat de los destinatarios de experiencias colectivas y que, además, inciten las prácticas autogestionarias y cooperativas de los mismos. Si bien en gran parte de las experiencias se lograron colar pautas culturales y criterios de hábitat mediante la participación social, aún se introdujeron desde los parámetros y pautas culturales de los arquitectos. Las viviendas cooperativas fueron concebidas por los arquitectos y reformada esa con- 
cepción por los destinatarios mediante un proceso de re-apropiación de los proyectos, pero no fueron concebidas desde su génesis por los usuarios con acompañamiento de los profesionales. Este es el caso de las cooperativas señaladas en la Figura 4.

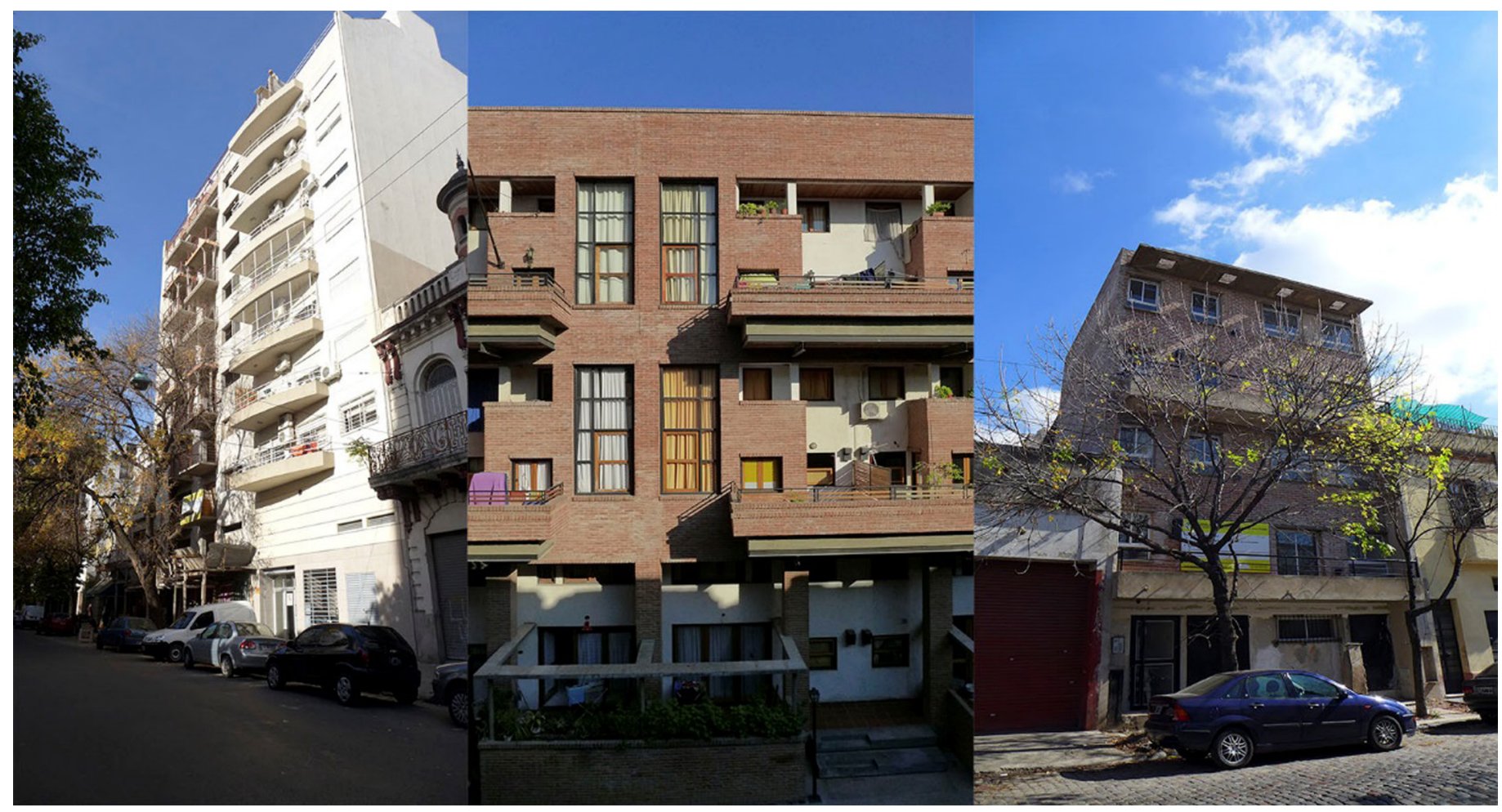

Ahora bien, dentro de las experiencias del PAV también se verificó unos pocos casos en los que el proceso de diseño fue "deliberativo" (De la Mora, 1992, 2002) y con altos niveles de participación (Ilari, 2003). Estas experiencias desarrollaron incipientes prácticas de diseño participativo $^{8}$ a través de talleres colectivos, en donde los destinatarios diseñaron sus viviendas desde pautas culturales propias y con el apoyo y acompañamiento técnico de los arquitectos. En estos casos, la participación social se gestó como un espacio de apropiación del ejercicio del derecho a una vivienda digna y a un hábitat adecuado (Rolnik, 2011). Una de las potencialidades que ofrece el Programa es la posibilidad de diseñar proyectos a tamaño y características de las familias que luego harán uso de las viviendas. En función del modo en el que se ejerza la autogestión y el rol del arquitecto, el programa habilita cierta permeabilidad a gustos y preferencias de los usuarios, generando condiciones para un mejor resultado social de la política (contemplando la composición de la familias por cantidad, sexo y edad, previendo constructivamente impedimentos físicos de algún integrante, preferencias de diseño y posibilidades de crecimiento interno de las viviendas, e incluso diseño de espacios colectivos, definiendo localización, eligiendo vecinos, entre otros).

En cuanto a la instancia de producción constructiva de las viviendas, las experiencias de autogestión del PAV también mostraron variabilidad según las características que asumió cada cooperativa. Hubo cooperativas que decidieron encarar sus obras y autogestionar los recursos estatales mediante la contratación de empresas constructoras - tal cual programa "llave en mano"- Este fue el caso de la Coop. El Palomar, la cual se desentendió por completo del proceso de obra y solo asu-
Figura 4: Coop. Construyéndonos, Coop. El Molino (MOI-Movimiento de Ocupantes e Inquilinos) y Coop. Emergencias. Fuente: Tomas propias junto a Kaya Lazarini, 2013.

$8 \quad$ El diseño participativo remite a una metodología proyectual, donde la pericia del profesional arquitecto se pone disposición de destinatarios activos de las viviendas. Mediante actividades participativas de taller se facilita el diálogo y la comprensión de las necesidades de hábitat de cada comunidad, se despliegan actividades dinámicas de diseño, dibujos, modelos físicos y virtuales, como también debates conceptuales acerca de la función social de la propiedad, la vivienda y - hasta- la lucha por el derecho al hábitat y a la ciudad. En este sentido, en la arquitectura autogestionaria, la participación los deseos y necesidades de los destinatarios son prioritarios y resultan ordenadores del proceso de diseño (Usina Centro de trabalhos para o ambiente habitado, 2012). 
mió la responsabilidad de la transferencia de fondos a la empresa tras la certificación de los avances de obra realizada por los inspectores del IVC. La/os cooperativistas deslindaron en la empresa la responsabilidad de la compra de los materiales de construcción, la contratación de la mano de obra, la mayoría de las definiciones de diseño, el control de la calidad de las instalaciones, la elección de las terminaciones, entre otras cuestiones [Entrevista Referente Coop. El Palomar-PAV. CABA. Junio 2013]. Pero esta cooperativa no fue un caso común entre las experiencias del PAV.

En la mayoría de las experiencias intervinieron en la producción empresas pequeñas y/o familiares, e incluso, algunas cooperativas pivotearon durante alguna etapa de la producción con tareas de autoconstrucción que encararon los propios cooperativistas guiados por los arquitectos de los ETIs y experimentaron instancias de ayuda mutua. Este fue el caso de las cooperativas del Movimiento de Ocupantes e Inquilinos (MOI), Cooperativas Caminito, Uspallata y gran parte de las organizaciones sociales. Estas prácticas de involucramiento en el proceso de obra permitieron a los cooperativistas llevar un control minucioso de los gastos, ejercer prácticas de ahorro mediante la ejecución de tareas con poca dificultad de obra y hacerse cargo de la compra y acopio de materiales (lo que les permitió implementar políticas de búsqueda de precios). Inclusive, para la ejecución de la obra, la cooperativa EMETELE (del Movimiento Territorial de Liberación -MTL-) fundó su propia empresa (Empresa Constructora EMETELE Ltda.), en donde todas las decisiones (ya sean técnicas, de tiempos de realización del trabajo voluntario, de interrupciones de obra, compra de materiales, etc.) se tomaron de manera asamblearia permitiendo así mantener un diálogo permanente entre los miembros de la empresa y los integrantes de la cooperativa. Otro ejemplo es el MOI, el cual creó su propia cooperativa de trabajo para impulsar las obras de sus cooperativas de vivienda combinando prometedores procesos de ayuda mutua (Coops. El Molino, La Fábrica, Perú y Yatay).

Por ende, en las experiencias autogestionarias del PAV, se verificó que el modo de organización interno de cada cooperativa marcó diferencias en cuanto en la intensidad (Cabrero, 2004) y en el grado (Ilari, 2003) de la participación social. Los lineamentos participativos del programa no tuvieron expresión de la misma manera en todas las cooperativas, sino que las decisiones tomadas en los procesos autogestionarios encontraron estrecha vinculación con las capacidades desarrolladas hacia el interior de cada organización. Estas capacidades internas habilitaron y/o obstruyeron procesos más o menos participativos en la etapa de la producción de las unidades de vivienda. A mayor involucramiento de los destinatarios de la vivienda en el proceso autogestionario, mayor fue la participación desplegada por sus cooperativistas en el diseño y construcción de sus proyectos constructivos. Incluso se verificó que las cooperativas que tuvieron altos niveles de participación en el diseño de sus viviendas, mantuvieron ese correlato en la etapa productiva.

Lo que buscaremos demostrar en el apartado siguiente, es que aquellas cooperativas que contaron con reales instancias de participación social en los diseños de las viviendas y en la etapa productiva de las mismas lograron transitar procesos de apropiación que tuvieron repercusiones en los asociativismos vecinales construidos en la etapa del habitar para el cuidado y mantenimiento de sus cooperativas. 
Resultados. El "habitar" de la vivienda cooperativa: génesis para un asociativismo vecinal autogestionario

El desarrollo de la vida cotidiana en el marco del asociacionismo vecinal es uno de las principales problemáticas de la vivienda estatal identificada por numerosos estudios sobre la temática (Gentilini et al., 2004; Girola, 2007; Giglia 2012; Dunowicz y Boselli, 2018). El habitar de los complejos cooperativos y sus espacios comunes implicó un enmarañado entramado de mediaciones entre lo privado, lo común y lo público, donde la gestión de los desacuerdos, junto a las dificultades de optimizar los usos de los espacios y servicios comunes y el mantenimiento de lo construido, impacta en las relaciones vecinales que se construyeron entre cooperativistas de los complejos. Por lo que el incesante solapamiento de los diversos habitus (Bourdieu, (1999[2010]) individuales/ familiares y el asociacionismo vecinal construido en experiencias de producción de vivienda estatal se constituyó en un fenómeno que merece atención, pero más aún en procesos que se gestaron de manera autogestionaria en el marco de cooperativas de vivienda, en donde procesos de participación social permean esas instancias del habitar.

El análisis corroboró que en las cooperativas de vivienda analizadas donde hubo un trabajo previo — en el marco del área social del ETIacerca de la convivencia cooperativa y la relación vecinal — que fueron la mayoría de ellas-, los resultados en la etapa del habitar fueron muy satisfactorios. Las cooperativas del PAV mostraron la especificidad que al momento de iniciar la convivencia, a diferencia de las experiencias "llave en mano", los futuros vecinos ya se conocían por haber compartido una trayectoria de habitar previa (muchos convivían en hoteles o conventillos), por haber participado en la gestación de la Ley 341 y la lucha por el acceso a la vivienda digna, por su involucramiento en las etapas de diseño y construcción de las viviendas — como vimos en el apartado anterior-, y por la construcción social que tuvieron que emprender para consolidar sus cooperativas a lo largo de todo el proceso de construcción del hábitat. En numerosas entrevistas se registró como punto inicial del "habitar cooperativo" la etapa de conformación legal de la cooperativa en el INAES - Instituto Nacional de Asociativismo y Economía Social- y/o la búsqueda de los terrenos a comprar para construir (en lugar de señalar el momento de las mudanzas y toma de posesión de sus viviendas). Incluso, en el marco de los ETIs, se trabajó fuertemente en la consolidación de buenas prácticas vecinales ancladas en actitudes positivamente valoradas entre los vecinos cooperativos (la cordialidad, la tolerancia, el respeto por el otro, la flexibilidad, el no meterse en los asuntos ajenos). ${ }^{9}$ Esta trayectoria cooperativa previa repercutió en el asociativismo vecinal resultante. Salvo excepciones, gran parte de los testimonios recogidos dieron cuenta de buenas convivencias vecinales (más allá de los roces y/o rispideces de la convivencia diaria) que encuentran origen en aquellas trayectorias previas de convivencia pre-cooperativa:

(¿Cómo es la relación vecina que tienen ahora que conviven?) Y nosotros ya sabíamos cómo iba a ser, la mayoría ya nos conocíamos... Con la social hablábamos acerca de la convivencia, el compromiso, cómo nos íbamos a organizar... La gente comprometida cuida y quiere que el lugar donde vive sea cada día mejor, cuando vos no lo luchaste, te cuesta entender y te cuesta comprometerte, esa es la situación. A los que nos costó tanto, los que luchamos tantos años y sacrificamos tantas cosas por esto queremos
9 Estas actitudes fueron indicadas por diversos cooperativistas consultados como actitudes que refuerzan una buena convivencia. 
que esto sea cada día mejor, porque después viene la otra generación, que son nuestros hijos y después nuestros nietos, uno quiere dejarles algo bueno [...]. Acá nosotros hicimos un código de convivencia interno para asociados, no se copió de ningún lado, cada uno decíamos cómo queríamos vivir, y ese código de convivencia tiene varios puntos. Nosotros acá ya hace como 5 años que vivimos y pasaron muchas cosas, lindas y otras muy desagradables $[\ldots]$, pero bueno, todos tenemos alguna pequeña diferencia, pero si lo ves en forma total, está bien. Yo veo que en todos lados de convivencia las diferencias están, pero dentro de todo es positivo acá [...] fuimos aprendiendo a convivir desde el principio, cuando todavía no éramos vecinos (Entrevista referente Cooperativa Uspallata. CABA. Mayo 2013).

Ya nos conocíamos, por las reuniones de la cooperativa en la etapa de obra [...]. Acá el único tema es la plata, después en general es buena la convivencia, van a hacer 10 años. Acá hay convivencia, hay respeto y comprensión (Entrevista Referente Cooperativa 28 de junio. CABA. Mayo 2013).

No obstante lo señalado, la relación vecinal no deja de ser un canal de expresión de los pequeños y grandes agravios, las amistades y alianzas, las simpatías y antipatías del convivir cotidiano de los usuarios de las viviendas cooperativas. Entre las experiencias autogestionarias, por ser experiencias de convivencia de carácter más colectiva, donde la cotidianidad de la relación vecinal se vivencia con mayor intensidad en el día a día por el doble rol que desempeñan (de ser vecinos y a la vez cooperativistas), el peso del mal vínculo llevó —en algunos casos-a influenciar sobre la preferencia de abandonar el proyecto cooperativo e irse de sus viviendas:

Por la vivienda no [responde ante la pregunta si se iría de la casa]. Ahora si fuera por los vecinos, sí me voy. Yo lo quiero a este edificio [...] nosotros todo ese tiempo [en referencia a los años de construcción del edificio] dejamos de hacer cosas nuestras, por ejemplo de trabajar, porque no nos daba tiempo de ir a trabajar, todo el día en el instituto [en referencia al Instituto de la Vivienda de la Ciudad —IVC—]... Nosotros dejamos un montón de cosas para tener lo que tenemos, pero le pasa a todos [...] esto te lleva mucho tiempo. Nosotros a las 10 de la mañana ya estábamos ahí en el IVC, hacíamos marchas, yo me llevaba a mis hijos, un día fuimos y le tiramos huevos a Ibarra para que nos atendiera (risas). Uno hace un montón de cosas por esto y yo estoy orgullosa de tener mi casa. (Pero entonces, si vos tuvieras la posibilidad de irte, ¿te irías?) Sí, me iría. (¿Por la relación con los vecinos?) Si, por ellos. (¿Por la vivienda no?) Por la vivienda no, yo lo quiero a este edificio. (Los vecinos influyen...) Antiguamente me afectaban mucho $[\ldots]$. No valoran lo que tienen, en serio no sé cómo es o por ahí no se dan cuenta porque todos venimos en casa tomada, no es que salimos de un departamento y vinimos acá. La gente que vino acá viene toda de hotel o casa tomada y no valoran lo que tienen, yo en las reuniones les digo, "nosotros tenemos Constitución por ejemplo a 5 cuadras, estamos frente a una plaza, tenemos centros de salud, tenemos hospital, tenemos todo acá", y la gente no lo valora. Pero es como que parece que no lo quieren [Entrevista A5. PAV. Cooperativa Alto Corrientes. CABA. Abril 2013].

Me iría del lugar. (¿Por qué? ¿No te gusta la vivienda?) Son comodísimos los departamentos [...]. Pero hoy en día, sí me iría. Hicimos todo acá con tanto cariño, tanta alegría, cuando pararon la obra llorábamos todos. Íbamos a dormir ahí para que no nos roben el poco material que quedaba, dormía en la obra. (Mucho sacrificio...) [El entrevistado se emociona] Demasiado [...]. Yo estoy muy decepcionado, sacrifiqué mi vida por esto, tra- 
bajo [...]. Hay gente en el consejo que me apoya y el resto no [...]. Estoy muy desmoralizado por la gente. Yo pienso pagar lo más rápido que pueda y vender e irme. He llegado a esa conclusión porque vos tenés que pasar 30 años de convivencia con ellos para pagar el crédito, pero hay gente que no vale la pena, esta gente que no quiere pagar el crédito, que nunca valoro el trabajo que hice acá, lo que se hizo, ese techo que está recibiendo casi gratis. Hay una escalera principal que va a todos los pisos y yo me los cruzo todos los días ahí. Entonces uno llega a la puerta de su casa y piensa esas cosas, en estos sin vergüenza. Yo me iría (Entrevista A2. PAV. Coop. Luz y Progreso. CABA. Abril 2013).

Estos testimonios remiten a casos puntuales dentro del grupo de cooperativistas entrevistados. Sus cooperativas, en la etapa de ejecución de obra mostraron una fuerte delegación de obligaciones autogestionarias sobre el consejo de administración de la cooperativa (más específicamente, en sus presidencias), desligándose —el resto de los integrantes de la misma- de la construcción cotidiana de la participación colectiva. Esto pareciera haber tenido consecuencias de peso en las posibilidades de apropiación de las viviendas por el resto del colectivo y en el asociativismo vecinal de las instancias del habitar.

También verificamos como una variable de peso la escala de los complejos habitacionales cooperativos. En los complejos habitacionales más pequeños, la relación vecinal se vivió por los entrevistados de manera más intensa. Al tratarse de grupos reducidos de familias entre las que hay que organizarse para afrontar los diversos problemas de la cotidianidad de los complejos, los conflictos suelen vivenciarse con mayor intensidad. Pero también hay que tener en cuenta que en los complejos en los que surgieron estos asociativismos vecinales negativos remitió a proyectos en los que la relación vecinal no refiere únicamente a la convivencia de la etapa del habitar, sino que remiten también a esa trayectoria previa de lucha por el acceso a la vivienda, que como toda disputa asumió un perfil conflictivo y generador de rispideces que se acentuaron en la convivencia cotidiana del habitar cooperativo.

Evidentemente, la construcción de asociativismos vecinales positivos o negativos para el ejercicio de los cuidados de la convivencia cooperativa, la optimización de los usos de los espacios y servicios comunes y el mantenimiento de los complejos habitacionales está influenciada por la trayectoria previa de diseño y construcción de las viviendas. La/ os cooperativistas iniciaron allí una instancia pre-cooperativa en la que la toma de decisiones vinculadas al ejercicio autogestionario fue construyendo vínculos colectivos previos a la convivencia que, en el habitar, repercuten en la apropiación de las viviendas y los complejos y en la construcción de estos asociativos vecinales.

Ahora bien, más allá de que se trate de cooperativas con relaciones vecinales positivas o negativas, todas despliegan, en la etapa del habitar, estrategias de organización para el mantenimiento de los complejos, sostienen una caja común para gastos eventuales y coordinan asambleas para el tratamiento de problemas y/o eventualidades de la vida cotidiana cooperativa. Todos los entrevistados consultados vincularon el sostenimiento de estas prácticas de cuidado con la trayectoria precooperativa vivida y la re-interpretan como una continuación de la etapa de diseño y posterior obra de las viviendas.

En otro orden de registro, la relación entre los usuarios de las viviendas cooperativas con los vecinos de los barrios en los que se emplazaron los complejos autogestionarios, es decir, con los vecinos externos, 
al igual que los destinatarios de la vivienda social tradicional producida por el Estado, tampoco se presentó sencilla. El modo en que fueron contemplados desde "afuera" también surgió como una preocupación para algunos de entrevistados.

En el imaginario colectivo, la vivienda social es clasificada en las antípodas del ideal de vivienda y, por tratarse de una vivienda producida por el Estado, contribuye a calificar a sus usuarios negativamente, por considerarlos "beneficiarios" ${ }^{10}$ de un bien tan preciado como es una vivienda. El estigma creado alrededor de una vivienda social y de las personas que viven en ellas se resumen en el supuesto, dice Giglia (2012, p. 174), “de falta de cultura, de educación, de civilidad, de buenos modales y de incapacidad para relacionarse con los demás de manera pacífica y discreta, sin el autocontrol suficiente como para poder comportarse en un marco de civilidad". Esta supuesta incivilidad imputada al usuario de una vivienda estatal también suele estar asociada, dice la autora, al estigma de un lugar hacinado, al que se le atribuye la falta de mantenimiento y de orden. Se les asigna a sus usuarios malos hábitos y costumbres, por ser sucios, groseros, incultos y negros (como usualmente el sentido común dominante rioplatense suele describir a los habitantes de tipologías habitacionales informales o de vivienda social). Pero también, este estigma encuentra estrecha relación a un temor de raíz netamente económico, derivado de una posible depreciación de los valores de los inmuebles del barrio por la llegada de estos proyectos de vivienda.

A pesar que los edificios cooperativos difícilmente puedan ser identificados en el tejido urbano de la cuadra porque sus tipologías constructivas se mimetizan con la trama, también se dieron situación de estigmatización social por parte de sus vecinos externos. Esto llevó a que algunas cooperativas ejecuten prácticas de invisibilización de sus edificios cooperativos para evitar ser identificados como vivienda social:

Por las cooperativas que hay en barrio, las de la Lechería, la mía, se puso en alerta todo el barrio de Mataderos y hubo una reunión en Miralla y Eva Perón y ahí fuimos varios cooperativistas a explicarles que no era que los cooperativistas éramos delincuentes o gente que roba, que era otra cosa, un proceso. Les explicamos a los vecinos del barrio, gente de poder económico porque estaban en autos, con micrófono, pensando cómo defenderse, como echar a las cooperativas del barrio de Mataderos. (Ah, bueno, ¿pero la resistencia fue organizada entonces?) Si mucha. Y nosotros fuimos y escuchamos lo que decían. Sabían dónde quedaban las cooperativas, las tenían identificadas y sabían quiénes eran los presidentes. Cuando mencionaron Luz y Progreso, mencionaron mi nombre, entonces yo usé mi palabra y les dije que lo que ellos estaban diciendo era falso, la cooperativa está inaugurada en Mataderos hace ya un año y pico y ni siquiera se enteraron, porque somos gente de trabajo y no son sucuchos como ellos decían... (Entrevista Referente Cooperativa Luz y Progreso. CABA. Abril 2013).

No, acá no se enteró nadie, nadie se enteró [...]. Al otro día que pusieron el cartel amarillo [en referencia al cartel del IVC que señala el nombre del programa] lo hice sacar, pero no fue por maldad, sino porque no vaya a ser cosa que algún ojo audaz lo vea y después nos discriminen por eso [...] lo puse allá arriba, donde nadie lo vea y ya (Entrevista Referente Cooperativa Octubre. CABA. Mayo 2013).

10 Se evita la utilización de esta palabra en este artículo por considerar que la misma niega la condición de derecho del acceso a la vivienda y, además, esconde la condición crediticia en la que quedan envueltos sus destinatarios.

Cooperativas que forman parte de organizaciones sociales más amplias, por la escala de sus emprendimientos (en general, suele tratarse de cooperativas grande, de más de 100 viviendas), no pudieron pa- 
sar desapercibidos en sus barrios inserción y fueron estigmatizados por parte del entorno barrial (Carman, Vieira da Cunha y Segura, 2013). Solo con el paso del tiempo y la ejecución de estrategias de integración social por parte de las propias organizaciones lograron revertir tal situación inicial. Este fue el caso de la cooperativa El Molino (del MOI), la cual, mediante la construcción de un programa de jardín maternal y un bachillerato popular para adultos, generaron espacios de integración de sus cooperativistas con los vecinos del barrio, quienes finalmente tuvieron una alta representación entre los estudiantes que recurrieron a estos espacios de formación. También se impulsaron actividades culturales y festivales que propiciaron la apertura del complejo hacia el barrio para desbaratar ese prejuicio inicial. Las estigmatizaciones se dieron con anterioridad a la llegada de la/os cooperativistas a la vivienda, sustentadas en un prejuicio hacia el hecho de tratarse de viviendas de interés social. Según Giglia (2012) el estigma basado en un prejuicio, es decir en un juicio emitido sin una comprobación empírica, genera efectos de barrera simbólica entre un "nosotros" y un "ellos", es decir entre los integrados a la trama urbana (y al patrón habitacional y cultural de la cuadra en que se insertaron los edificios) y los cooperativistas recién llegados, quienes implementaron estrategias conscientes de integración para, con el paso del tiempo, disipar estos estigmas.

\section{Conclusiones}

El artículo tuvo por objetivo analizar los escenarios de participación social experimentados por distintas experiencias autogestionarias del Programa de Autogestión de la Vivienda en relación con las características que asumió el asociativismo vecinal durante el habitar de las cooperativas. A partir de una metodología cualitativa de análisis, lo que se trató de demostrar es que en aquellas cooperativas en las que se lograron desplegar reales procesos de participación social durante las etapas de diseño y producción de las viviendas, la construcción de relaciones vecinales propias del habitar se vio facilitada por aquella trayectoria, tanto en la consolidación de las prácticas cotidianas de cuidado de sus edificios como en la resolución de conflictos, redundando esto en procesos positivos de apropiación de lo construido.

En el plano de la vida cotidiana verificamos que el asociativismo vecinal hacia adentro de los complejos cooperativos como hacia afuera, con el entorno barrial, varió en función a las características que asumió cada proceso cooperativo y en función de la construcción social desarrollada por cada una de ellas. Con relación a los vecinos internos se verificó que la práctica compartida de participación en la etapa del diseño y la construcción de las viviendas cooperativas, allanó las posibles incompatibilidades de esta relación o al menos les aportó más herramientas para afrontar las conflictividades. La construcción de un colectivo a la par de la materialización de las viviendas cooperativas abonó al desarrollo de asociativismos vecinales más positivos (que el existente en los complejos de vivienda estatal tradicional) a partir de saludables relaciones vecinales (expresada en una buena convivencia vecinal). El trabajo previo a la convivencia realizado por el área social de los ETIs de las cooperativas se constituyó en factor de importancia que favoreció la construcción de buenas relaciones vecinales. El establecimiento de modalidades organizativas previas (como reglamentos de convivencia y/o taller de formación vecinal) para la etapa del habitar y el man- 
tenimiento de los edificios se verificó que contribuye a una mayor apropiación de lo producido y una mejor integración social hacia el interior de las organizaciones. Existe una clara conciencia entre la/os cooperativistas que un buen cuidado de los complejos habitacionales evita dinámicas de estigmatización social que puedan desencadenar, además, en segregación socio-urbana (Carman et al., 2013).

En los casos en los que los asociativismos vecinales se expresaron de manera negativa, también verificamos efectos de la etapa previa - constructiva - en la etapa del habitar de las viviendas cooperativas. Al haberse iniciado, el habitar, con anterioridad a la etapa de la convivencia, conflictos irresueltos del pasado tuvieron eco en malas convivencias vecinales (que, además, en complejos más pequeños, se vivió de manera más intensa y abigarrada e impactó en las posibilidades de apropiación).

En relación con el segundo eje de análisis, la relación vecinal con el entorno barrial, encontró correlación con la capacidad de invisibilización de la condición de "social" de las cooperativas de vivienda. El tamaño y el diseño constructivo (y estético) de las cooperativas tuvieron impactos en las condiciones generadas para la integración social a escala barrial. Así, cooperativas que tomaron escala (más de 100 viviendas) y a las que se les dificultó esconder su condición de vivienda social, fueron recibidas en el barrio a partir de proceso de estigmatización social que debieron revertir mediante políticas de integración desplegadas por las propias cooperativas. El hecho de tratarse de viviendas sociales se constituyó en un factor objeto de estigmatización por parte de los vecinos colindantes (Carman et al., 2013).

Otro fue el cantar de las cooperativas con escalas constructivas más pequeñas y con correlación hacia los patrones habitacionales y culturales de su barrio de inserción (Giglia, 2012). Estas condiciones admitieron procesos de solapamiento de las cooperativas en el tejido urbano de inserción y estrategias de invisibilización de su condición de vivienda social; cuestión que permitió evitar dinámicas de segregación social hacia los destinatarios de las viviendas cooperativas y redundaron en buenas relaciones vecinales con el entorno. Pues evidentemente, la estrategia de hacer inidentificable a la vivienda social en el entramado de la cuadra, desarticula dinámicas estigmatizadoras, habilitando canales para una más aceitada integración social.

Los resultados de este análisis creemos aportan a los debates actuales de la autogestión, la participación social y el asociativismo vecinal; pero fundamentalmente aporta evidencia concreta a la necesidad de que los estados apoyen (con recursos) este tipo de experiencias - alternativas- que muestran resultados superadores en relación con la producción de vivienda estatal. 


\section{Referencias bibliográficas}

Barreto, Miguel Ángel (2008). La comprensión del problema habitacional desde una perspectiva compleja para un abordaje integral. ULACAV, XIV Encuentro de la Red Universitaria de Cátedras de Vivienda. [CD ROM] Buenos Aires: Edición FADyU-UBA.

Bourdieu, Pierre (1999[2010]). Efectos de lugar en la miseria del mundo. México: FCE.

Cabrero, Enrique (2004). Cogestión gobierno-ciudadanía en programas de bienestar social en el espacio municipal. Un balance preliminar. En Ziccardi, Alicia (Ed.), Participación ciudadana y políticas sociales en el ámbito local (pp. 115-132). México DF: UNAM.

Carman, María, Vieira da Cunha, Neiva y Segura, Ramiro (2013). Segregación y diferencia en la ciudad. Quito/Buenos Aires: FLACSO, CLACSO y Ministerio de Desarrollo Urbano y Vivienda. Recuperado el 3 de abril de 2021 de: http:/ / biblioteca.clacso. edu.ar/clacso/gt/20140707123234/segregacionydiferencia.pdf.

Casgrain, Antoine y Janoschka, Michael (2013). Gentrificación y resistencia en las ciudades latinoamericanas. El ejemplo de Santiago de Chile. Andamios, 10(22), 19-44.

De la Garza, Muna M. (2014). Transformaciones urbanas y procesos de gentrificación desde la resistencia. Aproximaciones a un movimiento vecinal en la Barceloneta, Barcelona. Working Paper Series. Serie (I). Gentrificación, resistencias y desplazamiento en España. Recuperado el 2 de junio de: http:/ / contestedcities.net/working-papers/wp-content/uploads/ sites/8/2014/03/WPCC-14012_MakhloufMuna_ Transformaciones-desde-la-resistencia.pdf.

De la Mora, Luis (1992). Porvenir local. Participación popular en la conquista de ciudadanía. Evaluación de procesos de participación en el Plan de Recuperación de barrios marginales de Recife (Brasil) [Tesis Doctoral). Universite de Paris I Panthéon-Sorbonne, París, Francia.

De La Mora, Luís (2002). Aferição da qualidade da participação dos agentes envolvidos em mecanismos de gestão democrática do desenvolvimento local. Uma proposta metodológica. En Lacerda, Norma y Leal, Suely (Eds.), Relação público-privado: do local ao global, surgimento de novos atores na gestão das políticas públicas (pp. 2-16). Recife: UFPE.

Delgadillo Polanco, Victor Manuel (2009). Patrimonio urbano y turismo cultural en la ciudad de México: Las Chinampas de Xochimilco y el Centro Histórico. Andamios, 6(12), 69-94.

Dunowicz, Renée y Boselli, Teresa (2018). Habitar en la vivienda social de Buenos Aires. En Borthagaray Juan Manuel (Ed.). Habitar Buenos Aires, las man- zanas, los lotes y las casas. Buenos Aires: Ediciones FADU.

Espagnol, María José y Echeverría, Andrea (2010). Las organizaciones territoriales y el proceso histórico de urbanización e industrialización en el área metropolitana. En Bráncoli, Javier (Ed.), Donde hay una necesidad, nace una organización. Surgimiento y transformaciones de las asociaciones populares urbanas (pp. 71-104). Buenos Aires: Ediciones Ciccus y Facultad de Ciencias Sociales-UBA.

Fernández Wagner, Raúl (2009). Elementos para una revisión crítica de las políticas habitacionales en América Latina. En Assentamentos informais e moradia popular: subsidios para politicas habitacionais mais inclusivas (pp. 1-28). Brasilia: IPEA.

Gentilini, Javier, Bettanin, Cristina, Saraceni, Romina, Lennie Bruno, Matías, Olejarczyk, Romina y Enríquez, Celina (2004). Sustentabilidad del hábitat en los complejos de vivienda social de la Ciudad de Buenos Aires y responsabilidad del Estado frente al régimen legal de propiedad horizontal. En VI Jornadas de Sociología. Facultad de Ciencias Sociales, Universidad de Buenos Aires, Buenos Aires. Recuperado el 2 de mayo de 2021 de: https:/ / cdsa.aacademica.org/000-045/794.pdf.

Giglia, Ángela (2012). El habitar y la cultura. Perspectivas teóricas y de investigación. Barcelona: Anthropos Editorial.

Girola, María Florencia (2007). Procesos de apropiación del espacio y sociabilidad vecinal en un gran conjunto urbano situado en la ciudad de Buenos Aires. Anthropologica, 25(25), 131-156.

Grafmeyer, Yves (1998). Logement, quartier, sociabilité. En Bonvalet, Catherine, Brun, Jacques y Segaud, Marion (Eds.), Logement et habitat: l'état des savoirs (pp. 347-354). Paris: La Découverte.

Ilari, Sergio (2003). Construcción de viviendas y de organización social. Evaluación de los resultados de un programa de habitar popular. Buenos Aires: Ed. Universidad Nacional de Luján.

Lefebvre, Henri (2003). La producción del espacio. Madrid: Capitan Swing.

Newman, Kathe y Wyly, Elvin K. (2006). The right to stay put, revisited: gentrification and resistance to displacement in New York City. Urban Studies, 43(1), 23-57. DOI: https://doi. org/10.1080/00420980500388710.

Ortiz Flores, Enrique (2002). La producción social del hábitat: ¿opción marginal o estrategia transformadora? En Ortiz Flores, Emilio y Zarate, María Lorena (Eds.), Vivitos y coleando. 40 años trabajando por el hábitat popular de América Latina (pp. 188-196). México: Universidad Autónoma de México. 
Pedro, Beatriz, Campari, Gabriela, Di Virgilio, María Mercedes, Rodríguez, María Carla y Zapata, María Cecilia (2020). Construcción autogestionaria de hábitat por cooperativas: derecho a la ciudad y la centralidad en la Ciudad de Buenos Aires. Ley 341/00. Buenos Aires: PIUBAMAS (Programa Interdisciplinario de la Universidad de Buenos Aires). Recuperado el 4 de abril de 2021 de: http:/ /www.tlps.com.ar/wp-content/uploads/2020/08/Construccion-autogestionaria-de-habitat-por-cooperativas.pdf.

Pelli, Víctor Saúl (1997). La integración social como objetivo de las políticas públicas. Revista INVI, 12(31), 57-62. Recuperado el 23 de marzo de 2021 de: https://revistainvi.uchile.cl/index.php/INVI/ article/view/62070.

Pelli, Victor Saúl (2007). Habitar, participar y pertenecer. Acceder a la vivienda, incluirse en la sociedad. Buenos Aires: Nobuko.

Rodríguez, María Carla, Di Virgilio, María Mercedes, Procupez, Valeria, Vio, Marcela, Ostuni, Fernando, Mendoza, Mariana y Morales, Betsy (2007). Politicas del hábitat, desigualdad y segregación socio-espacial en el Área Metropolitana de Buenos Aires. Buenos Aires: AEU-IIGG/FSOC-UBA y HIC-AL.

Rodríguez, María Carla (2009). Autogestión, políticas de hábitat y transformación social. Buenos Aires: Editorial Espacio.

Rodríguez, María Carla y Di Virgilio, María Mercedes (2016). A city for all? Public policy and resistance to gentrification in the southern neighborhoods of Buenos Aires. Urban Geography, 37(8), 1215-1234. DOI: https://dx.doi.org/10.1080/02723638.2016. 1152844.

Rodulfo, María Beatriz (2003). La situación habitacional y las políticas públicas. Recuperado el 5 de noviembre de 2004 de: http:/ / www.urbared.ungs.edu.ar/ pdf/pdf-articulos/c2.pdf.

Rofman, Adriana (2007). Participación de la sociedad civil en políticas públicas: una tipología de mecanis- mos institucionales participativos. Tercer Sector y Sociedad Civil en América Latina y el Caribe-(Re) Pensando Identidades y Relaciones Intersectoriales, VI Conferencia Regional de ISTR Para América Latina y El Caribe, Salvador de Bahía, Brasil. Recuperado el 4 de abril de 2021 de: http:/ / biblioteca.municipios.unq.edu. ar/modules/mislibros/archivos/016.pdf.

Rolnik, Raquel (2011). Misión a la República Argentina (13-21 abril 2011), de la Relatora especial sobre la vivienda adecuada como elemento integrante del derecho a un nivel de vida adecuado, y sobre el derecho a la no discriminación en este contexto. San Pablo (Brasil): Programa de Naciones Unidas para los Asentamientos (ONU). Recuperado el 29 de agosto de 2021 de: http:/ / www.grupodemujeres. org.ar/descargas / tema\%20vivienda\%20onu.pdf.

Sautú, Ruth (1999). El método biográfico: la reconstrucción de la sociedad a partir del testimonio de los actores. Buenos Aires: Fundación Editorial de Belgrano.

Usina. Centro de trabalhos para o ambiente habitado (2012). Projeto de reassentamento da comunidade de Pequiá de Baixo.

Valles, Miguel (1999). Técnicas cualitativas de Investigación social. Reflexión metodológica y práctica profesional. Madrid: Síntesis.

Zapata, María Cecilia (2012). El Programa de Autogestión para la Vivienda: ¿Una política habitacional habilitante del derecho a la vivienda y a la ciudad? [Tesis de Maestría]. Universidad de Buenos Aires, Buenos Aires (Argentina). Recuperado el 4 de abril de 2021 de: http:/ / biblioteca.clacso.edu.ar/Argentina/iigguba/20120802051652/czapata.pdf.

Zapata, María Cecilia (2017). La politica habitacional porteña bajo la lupa. De los programas llave en mano a la autogestión del hábitat. Buenos Aires: Editorial Teseopress. Recuperado el 4 de abril de 2021 de: https://www.teseopress.com/politicahabitacio$\mathrm{nal} /$.

Zapata, María Cecilia (2021). Cooperativismo autogestionario de hábitat y asociativismo vecinal. El caso del Programa de Autogestión de la Vivienda de la Ciudad de Buenos Aires (Argentina). Hábitat y Sociedad, 14, 139-158.

<https://doi.org/10.12795/HabitatySociedad.2021.i14.08> 